\title{
1 Susceptibility of European freshwater fish to climate change: species profiling based on
}

\section{2 life-history and environmental characteristics}

3

4 Running head: European freshwater fish and climate change

5

6 Ivan Jarić ${ }^{1,2,3^{*}}$, Robert J. Lennox ${ }^{4}$, Gregor Kalinkat ${ }^{2}$, Gorčin Cvijanović ${ }^{3}$ and Johannes

7 Radinger ${ }^{2,5}$

8

$9{ }^{1}$ Biology Centre of the Czech Academy of Sciences, Institute of Hydrobiology, Ceske

10 Budejovice, Czech Republic

$11{ }^{2}$ Leibniz-Institute of Freshwater Ecology and Inland Fisheries, Berlin, Germany

$12{ }^{3}$ Institute for Multidisciplinary Research, University of Belgrade, Serbia

$13{ }^{4}$ Fish Ecology and Conservation Physiology Laboratory, Department of Biology, Carleton

14 University, Ottawa, Ontario, Canada

$15{ }^{5}$ GRECO, Institute of Aquatic Ecology, University of Girona, Spain

16

17 * Corresponding author: Ivan Jarić, Biology Centre of the Czech Academy of Sciences,

18 Institute of Hydrobiology, Na Sádkách 702/7, 37005 České Budějovice, Czech Republic, E-

19 mail: ivan.jaric@hbu.cas.cz, phone: +420 38777 5855, fax: +420 38531024

20

21 Keywords: IUCN; Red List; extinction threat; global warming; climate change.

22 
25 Abstract

26 Climate change is expected to strongly affect freshwater fish communities. Combined with

27 other anthropogenic impacts, the impacts will alter species distributions and contribute to

28 population declines and local extinctions. To provide timely management and conservation of

29 fishes, it is relevant to identify species that will be most impacted by climate change and those

30 that will be resilient. Species traits are considered a promising source of information on

31 characteristics that influence resilience to various environmental conditions and impacts. We

32 collated life history traits and climatic niches of 443 European freshwater fish species and

33 compared those identified as susceptible to climate change to those that are considered to be

34 resilient. Significant differences were observed between the two groups in their distribution,

35 life-history and climatic niches, with climate-change susceptible species being distributed

36 more southwardly within Europe, and being characterized by higher threat levels, lower

37 commercial relevance, lower vulnerability to fishing, smaller body size and warmer thermal

38 envelopes. We establish a list of species revealed to be of highest priority for further research

39 and monitoring regarding climate change susceptibility within Europe. The presented

40 approach represents a promising tool, to quickly assess large groups of species regarding their

41 susceptibility to climate change and other threats, and to identify research and management

42 priorities.

\section{Introduction}

As ectothermic organisms, fishes are intimately linked to local climatic conditions 
48 temperatures experienced in a given watershed (Pörtner \& Farrell, 2008; Isaak \& Rieman,

49 2013). Relative to seas and oceans, freshwater habitats are more drastically impacted by

50 changes in climate, especially due to changes in temperature and flow, and climate change is

51 projected to strongly affect freshwater fish communities (O'Reilly et al., 2003; Buisson et al.,

52 2008; Graham \& Harrod, 2009; Harrod, 2016; Radinger et al., 2017). Combined with other

53 anthropogenic impacts (e.g. land use change and thermal pollution; Radinger et al., 2016;

54 Raptis et al., 2017), climate change will restrict or redraw thermal envelopes, contribute to

55 population declines and local extinctions, and overall shifts in the distribution of species.

56 Riverine fish species losses due to climate change and reduced water discharge are predicted

57 to reach $75 \%$ in some river basins (Xenopoulos et al., 2005). Phenological changes in fish

58 behaviour (Otero et al., 2014; Dempson et al., 2017; Hovel et al., 2017) have been also

59 detected and emphasize the powerful changes imposed by a changing climate. In Europe,

60 there is a broad range of climatic conditions experienced across the landscape and a diverse

61 ichthyofauna distributed throughout the lakes and rivers (Ficke et al., 2007). Within the IUCN

62 (International Union for Conservation of Nature and Natural Resources) Red List, as much as

$6333 \%$ of European freshwater fish species are recognized as threatened by climate change

64 (IUCN, 2017).

Efforts to preserve ecosystem integrity must focus on maintaining species richness

66 and diversity to ensure that the services provided by freshwater ecosystems are maintained.

67 Conservation is often limited by funding and therefore must undergo triage to identify

68 priorities and allocate resources efficiently (McDonald-Madden et al., 2011). To provide

69 timely management and conservation and allocate resources efficiently, it is important to

70 identify those species that will be most impacted by climate change and those that might be

71 rather resilient. Species traits are considered as a promising source of information on 
72 characteristics that influence resilience to various environmental conditions and impacts

73 (Jiguet et al., 2007; Comte \& Olden, 2017b). Species traits represent any morphological,

74 physiological or phenological feature that is measurable at the individual level of a species

75 (Floeter et al., 2018). Trait-based evaluation has been demonstrated to be linked to the risk

76 status of species and can be used to investigate mechanisms that contribute to imperilment,

77 make predictions about unassessed species, or rank and prioritize species based on their

78 relative risk (Olden et al., 2007; Bland \& Böhm, 2016; Comte \& Olden, 2018).

79 Here we assess various ecological and life-history characteristics of European

80 freshwater fish species to identify traits that are characteristic for those that are susceptible to

81 the effects of climate change. Automated scraping of an online trait database and calculation

82 of climate envelopes using IUCN range maps overlaid on climate maps allowed us to collate

83 species-specific data on life history, distribution, climatic niches, as well as data on threat and

84 economic status. This allowed us to compare species identified as susceptible to climate

85 change with those that are considered to be resilient. Results of the study will contribute to a

86 better understanding of the expected climate change effects on European freshwater fish

87 fauna. We also establish a list of European species of highest priority for further research and

88 monitoring regarding climate change susceptibility. The method allows to extrapolate results

89 and characterize rare and less studied species, with scarce autecological information.

\section{Materials and methods}

92 Dataset

93 Our analysis comprised comparisons of in total 443 European freshwater fishes

94 between those that were identified as threatened by climate change $(n=148)$ within the IUCN

95 Red List Database (IUCN, 2017) and those without climate change listed as a threat ( $\mathrm{n}=295)$. 
96 A list of native European freshwater fish species belonging to 25 families, mainly to

97 Cyprinidae (45\%) and Salmonidae (20\%), was obtained from the IUCN Red List database

98 (IUCN, 2017). It included both exclusively freshwater species, as well as those that partly

99 enter brackish and saltwater. Obtained data also comprised IUCN Red List classification and

100 maps of their distributional range within Europe. In addition, we obtained information

101 whether climate change was indicated as one of the threats for each species, which is based on

102 threat analyses and expert judgement by IUCN species experts. Overall, the dataset comprised

$10333 \%$ species which were categorized as susceptible to climate change.

104 In addition, for each species we collated trait information related to their life

105 history, ecology, fishery and threat status, and spatial and bioclimatic data variables (Table 1).

106 Life-history data were obtained from the FishBase database (Froese \& Pauly, 2017) by using

107 the rfishbase R package (Boettiger et al., 2012, 2017). Traits with low data coverage (i.e.

108 those that were available for less than $1 \%$ of all species) were excluded from the analysis.

109 Bioclimatic spatial data were obtained from the MERRAclim database (Vega et al., 2017) and

110 included 19 variables related to temperature and humidity (Table 1). Global Human Footprint

111 map (map of anthropogenic impacts on the environment) was obtained from WCS and

112 CIESIN (2005) and the spatial elevation data were obtained from USGS (2010). Based on the

113 distributional range maps of each species (IUCN, 2017), mean values within each species'

114 range were estimated for each of the spatial variables using the intersect tool in ArcGIS

115 (version 10.5) and the extract function in the R (version 3.4.3; R Core Team, 2017) package

116 raster (version 2.6-7; Hijmans, 2017). Range maps were also used to estimate the number of

117 watersheds covered by each species based on WRI (2006), as well as the area and coordinates

118 of the range centroid for each species. General descriptive statistics and information on data

119 sources of all variables used in the analysis is presented in Table 1 and Supplementary 
120 material S1. The complete dataset is presented in Supplementary material S2.

121

122 Statistical Analysis

123 We calculated boosted regression trees (BRT) to evaluate the relationship between the

124 membership of a species to the group of susceptible vs. non-susceptible species and the 45

125 explanatory variables. BRT are a statistical learning method that combines and averages

126 (boosting) many simple single regression trees to form collective models of improved

127 predictive performance (Elith et al., 2008). BRT can accommodate continuous and categorical

128 variables, are not affected by missing values or transformation or outliers and are considered

129 to effectively select relevant variables, identify variable interactions and avoid overfitting

130 (Elith et al., 2008, Radinger et al., 2015).

131 Specifically, we first fitted an initial global BRT model (R package dismo, gbm.step,

132 version 1.1-4; Hijmans et al., 2017) using the complete set of explanatory variables. An

133 automatized stepwise backward selection of explanatory variables (gbm.simplify) was applied

134 to eliminate non-informative variables based on model-internal cross-validation of changes in

135 a models' predictive deviance (Hijmans et al., 2017). Thereafter, we calculated a final BRT

136 model (gbm.step) based on the selected set of explanatory variables. For all BRT modeling

137 steps, tree complexity and learning rate was set to 3 and 0.001 , respectively, to achieve the

138 recommended number of more than 1000 regression trees (Elith et al., 2008). All other model

139 settings were set to default or were automatically adjusted by the boosting algorithm. We

140 calculated a 10-fold cross validation of the BRT model as already implemented in the

141 algorithm. In addition, we extracted the mean AUC (area under the receiver operating

142 characteristic curve) as a measure of the model's predictive quality. The AUC is a threshold-

143 independent rank-correlation coefficient with high values typically indicating a strong 
144 agreement between the model prediction and the membership of species to the susceptible vs.

145 non-susceptible group (Hijmans \& Elith, 2017).

146 The relative importance (\%) of each explanatory variable in the final BRT model was

147 quantified based on the number of times each variable was used for splitting, weighted by the

148 squared improvement at each split and averaged over all trees (Elith et al., 2008). For BRT

149 models with Gaussian distribution the relative variable importance equals the reduction of

150 squared error attributable to a given variable. Differences between groups were also assessed

151 by bootstrapping, by sampling each group independently and estimating the difference based

152 on confidence intervals (functions two.boot and boot.ci, R package simpleboot, version 1.1-3;

153 Peng 2008). Differences were considered to be significant if $95 \%$ confidence intervals did not 154 overlap with zero.

155 Subsequently, species were ranked based on the subset of variables selected by the

156 BRT analysis (i.e., those with $>1 \%$ variable importance score), and weighed by the

157 importance of each variable, in order to estimate their position along the climate change

158 susceptibility continuum. For each species, the value of each variable was standardized based

159 on its position between the minimum $\left(t_{\min }\right)$ and maximum values $\left(t_{\max }\right)$ observed in the

160 dataset, with $0-1$ possible range, and multiplied by the importance score $\left(I_{x}\right)$ of the given

161 variable:

$162 R_{t x}=\frac{t_{x}-t_{\min }}{t_{\max }-t_{\min }} \times I_{x}$

163 where $R_{t x}$ represents the rank value of variable $t$ in species $x$, and $t_{x}$ is the value of variable $t$

164 for species $x$. For variables where the lower endpoint $\left(t_{\min }\right)$ is associated with the climate

165 change susceptibility, equation should be adjusted as follows:

$166 R_{t x}=\frac{t_{\max }-t_{x}}{t_{\max }-t_{\min }} \times I_{x}$ 
167 Summing of all ranking scores across all variables yielded the total species ranking score,

168 which can range from 0 to 100 , with higher values indicating stronger climate change

169 susceptibility.

170

171 Results

172 Our analyses indicated substantial differences between the two groups, climate

173 change susceptible versus non-susceptible species. The BRT analysis selected 35 most

174 relevant variables, which were subsequently assessed for their relative importance to

175 discriminate between the two groups (Figure 1 and Supplementary material S3). The BRT

176 model with the selected set of explanatory variables was successfully modeled

177 (Supplementary material S3) with a good cross-validated AUC of 0.87 (standard error $=$

178 0.014). Out of all explanatory variables, latitude of the species range centroid was selected as

179 by far the most relevant variable ( $31 \%$ variable importance), followed by the IUCN Red List

180 classification (8\%), commercial relevance (6\%) and vulnerability to fishing (6\%). Climate

181 susceptible species were characterized by more southwardly positioned distribution range

182 centroids $\left(41.6^{\circ}\right.$ vs. $47.8^{\circ} \mathrm{N}$ as a mean value in susceptible and non-susceptible species,

183 respectively), smaller range sizes $\left(175 \times 10^{3} \mathrm{~km}^{2}\right.$ vs. $\left.1686 \times 10^{3} \mathrm{~km}^{2}\right)$, and lower elevations

184 within their ranges (717.7 $\mathrm{m}$ vs. $892.2 \mathrm{~m}$ a.s.1.), with a higher proportion of exclusively

185 freshwater species (93\% vs. 66\%; Figure 2). Susceptible species were also characterized by a

186 smaller maximum body length $(23.4 \mathrm{~cm}$ vs. $41.0 \mathrm{~cm})$, higher proportion of threatened species

187 (63\% vs. $31 \%)$, lower proportion of commercially relevant species ( $25 \%$ vs. $74 \%$ of highly

188 commercial, commercial and minor commercial species), and lower vulnerability to

189 overfishing (32.6 vs. 38.5 vulnerability index; Figure 3), as well as by higher temperature-

190 related values (Supplementary material S4). Bootstrapping indicated significant differences 
191 between the groups in each of the variables. Species that are susceptible to climate change are

192 mainly distributed within the Mediterranean region, while the non-susceptible species

193 distribution mainly covers central and northern European regions, as well as the Carpathian

194 region (Figure 4).

197 top-ranked climate susceptible species were Acheron spring goby (Knipowitschia milleri),

198 Corfu toothcarp (Valencia letourneuxi), Iberochondrostoma almacai, Evia barbel (Barbus

199 euboicus) and Malaga chub (Squalius malacitanus). Most of the species with the high climate-

200 susceptibility ranks are also classified as highly threatened according to the IUCN

201 classification (Table 2). Interestingly, the highest ranked species, K. milleri, was not classified

202 within the IUCN Red List as threatened by climate change. Other high-ranking species that

203 were not recognized as threatened by climate change were Malaga chub (Squalius

204 malacitanus), Almiri toothcarp (Aphanius almiriensis), and Trichonis dwarf goby

205 (Economidichthys trichonis). Species with the lowest ranking scores, i.e. with low climate

206 change susceptibility, were humpback whitefish (Coregonus pidschian), Arctic flounder

207 (Liopsetta glacialis), northern pike (Esox lucius), burbot (Lota lota), and European perch

208 (Perca fluviatilis). A complete list of all species' rankings is presented in Supplementary

209 material S5.

\section{Discussion}

212 In the present study, significant differences in life-history and climatic niches were

213 observed between the European freshwater species susceptible to climate change and those

214 that are not, such as species body size, range size, distribution and thermal envelopes. The 
215 latitude of the species range centroid was by far the most influential trait. Overall, southern

216 regions with the warmer, Mediterranean climate comprised a higher proportion of species

217 susceptible to climate change (Figure 4). These results support recent findings that the species

218 from lower latitudes and tropical, warm-water habitats, are at greater risk from climate change

219 and warming (Payne \& Smith, 2016; Payne et al., 2016; Comte \& Olden, 2017b). In such

220 species, evolved towards higher upper thermal tolerances, specialization to thermal extremes

221 is accompanied by a reduced physiological flexibility and adaptation capacity to respond to

222 changing environmental conditions (Payne \& Smith, 2016; Payne et al., 2016; Comte \&

223 Olden, 2017b). Such heat-tolerant species are also adapted to temperatures close to their

224 physiological thermal limits, with a narrow safety margin for further temperature increases

225 (Sinclair et al., 2016; Comte \& Olden, 2017b). Freshwater basins in Southern Europe are also

226 of particular conservation concern due to an elevated pressure by a range of anthropogenic

227 impacts that further exacerbate effects of climate change, such as pollution, water resource

228 development and consumption, and biological invasions (Xenopoulos et al., 2005; Clavero \&

229 García-Berthou, 2005; Walther et al., 2009; Vörösmarty et al., 2010; Comte \& Olden, 2017a).

230 Climate-susceptible species were also characterized by a smaller body and range

231 size (Figures 2, 3). These traits, which are also related to a lower dispersal ability (Radinger \&

232 Wolter, 2014), are well recognized as predictors of climate change susceptibility in fish (e.g.

233 Ficke et al., 2007; Isaak \& Rieman, 2013; Chessman, 2013; Pearson et al., 2014; Radinger et

234 al., 2017). Smaller-bodied fish are facing elevated overall extinction risk in freshwater habitat

235 due to multiple threats, such as habitat loss and fragmentation (Olden et al., 2007; Kalinkat et

236 al., 2017; Kopf et al., 2017), which explains higher threat level observed in climate-

237 susceptible species in the present study. Observed lower commercial relevance and lower

238 vulnerability to fishing of climate-susceptible species both stem from a lower body size and 
239 related faster life history of such species.

240 It is important to acknowledge certain limitations of the data sources used in this

241 study, such as species and trait coverage, reliability of methods applied for threat and

242 extinction risk classification, and potential assessors' biases (Clavero \& García-Berthou, 2005;

243 Keith et al., 2014; Trull et al., 2018). Furthermore, species that are not classified within IUCN

244 Red List as threatened by climate change can comprise also those that are not yet assessed for

245 their major threats. Nevertheless, the focus of our study on a well-studied group such as

246 European species ensured that the basic life history data and IUCN Red List assessments were

247 mostly available (Kopf et al., 2017). IUCN Red List is sometimes considered to understate or

248 improperly account for climate change as a threat, mostly due to ambiguous definitions and

249 criteria (Trull et al., 2018). However, recent studies have indicated that the IUCN

250 classification is more efficient in detecting species vulnerable to climate change than

251 anticipated (Keith et al., 2014; Pearson et al., 2014). Notwithstanding all the caveats, the

252 databases used in the present study still represent the most comprehensive sources of data and

253 the best available knowledge (Olden et al., 2007; Vega et al., 2017).

254 Trait-based risk assessments are increasingly used for species profiling (Pacifici et

255 al., 2015; Liu et al., 2017; MacLean \& Beissinger, 2017). The approach presented in this study

256 might be considered a valid and promising approach to be used as a screening tool, i.e. to

257 quickly assess large groups of species regarding their susceptibility to climate change and

258 other threats based on species traits, and to identify research and management priorities. Our

259 results indicate that the European environmental policy related to climate change mitigation

260 and adaptation (EEA, 2012, 2017) should be mainly focused on Mediterranean region. This is

261 especially important since this region is also predicted to have the highest frequency of

262 droughts and extreme high temperatures, strongest reduction in precipitation and river 
263 discharges, the highest aggregate climate change impact and the lowest adaptation capacity

264 (Milly et al., 2005; Dankers \& Feyen, 2008; Fischer \& Schär, 2010; ESPON Climate, 2011;

265 Stagge et al., 2011; Rojas et al., 2012; Jacob et al., 2014; Russo et al., 2014). Moreover,

266 Mediterranean region was also identified as a European priority area regarding climate change

267 impacts for other species groups. A similar distributional pattern of species susceptible to

268 climate change was previously also reported for aquatic insects such as Plecoptera,

269 Ephemeroptera and Trichoptera (Hering et al., 2009; Conti et al., 2014), mammals (Levinsky

270 et al., 2007), as well as for terrestrial species in general (Pacifici et al., 2015).

$271 \quad$ Species ranking conducted here indicated priority species for further research and

272 monitoring regarding climate change (e.g. V. letourneuxi, I. almacai and B. euboicus; Table 2).

273 Moreover, it also identified species whose IUCN Red List status potentially needs to be

274 reconsidered or updated, such as highly ranked but apparently non-susceptible species (e.g. $K$.

275 milleri), or highly ranked species without a proper threat category (e.g. K. goerneri, classified

276 as Data Deficient species). As such, it has a potential to be used as a "Robin Hood Approach"

277 (Punt et al., 2011), where assessments based on information-rich species are used to evaluate

278 and categorize those that are information-poor. There is a need for climate change

279 vulnerability assessments that would be based on quantitative approaches and consistent set of

280 criteria, such as trait-based approaches advocated by IUCN (Foden et al., 2013; Trull et al.,

281 2018). The approach presented here could be a good step in that direction.

283 Acknowledgements

284 IJ acknowledges the sponsorship provided by the The J. E. Purkyně Fellowship of the

285 Academy of Sciences of the Czech Republic and funding from the European Union's Horizon

2862020 research and innovation programme through the project ClimeFish (grant No. 677039), 
287 as well as funding provided by the Alexander von Humboldt Foundation and the German

288 Federal Ministry of Education and Research (BMBF). GK acknowledges funding from the

289 BMBF through the project "GLANCE" (Global Change Effects in River Ecosystems; 01

290 LN1320A). JR acknowledges funding through the 2015-2016 BiodivERsA COFUND call for

291 research proposals and the Spanish Ministry of Economy, Industry and Competitiveness

292 (project ODYSSEUS, BiodivERsA3-2015-26, PCIN-2016-168). GC acknowledges funding

293 from the Ministry of Education, Science and Technological Development, Republic of Serbia

294 (grant number 173045). Thanks are extended to Ryder Burt for assistance with geographic

295 information processing.

297 References

298 Bland, L. M., \& Böhm, M. (2016). Overcoming data deficiency in reptiles. Biological

299 Conservation, 204, 16-22.

300

301 Boettiger, C., Lang, D. T., \& Wainwright, P. (2012). rfishbase: exploring, manipulating and

302 visualizing FishBase data from R. Journal of Fish Biology, 81, 2030-2039.

303

304 Boettiger, C., Chamberlain, S., Lang, D. T., \& Wainwright, P. (2017). Package 'rfishbase'. R

305 Interface to 'FishBase'. Version 2.1.2. https://github.com/ropensci/rfishbase. Accessed 15

306 January 2018

307

308 Buisson, L., Thuiller, W., Lek, S., Lim, P., \& Grenouillet, G. (2008). Climate change hastens

309 the turnover of stream fish assemblages. Global Change Biology, 14, 2232-2248. 
311 Chessman, B. C. (2013). Identifying species at risk from climate change: traits predict the

312 drought vulnerability of freshwater fishes. Biological Conservation, 160, 40-49.

313

314 Clavero, M., \& García-Berthou, E. (2005). Invasive species are a leading cause of animal

315 extinctions. Trends in Ecology \& Evolution, 20, 110.

316

317 Comte, L., \& Olden, J. D. (2017a). Climatic vulnerability of the world's freshwater and

318 marine fishes. Nature Climate Change, 7, 718.

320 Comte, L., \& Olden, J. D. (2017b). Evolutionary and environmental determinants of

321 freshwater fish thermal tolerance and plasticity. Global Change Biology, 23, 728-736.

322

323 Comte, L., \& Olden, J. D. (2018). Evidence for dispersal syndromes in freshwater fishes.

324 Proceeings of the Royal Society B, 285, 20172214.

325

326 Conti, L., Schmidt-Kloiber, A., Grenouillet, G., \& Graf, W. (2014). A trait-based approach to

327 assess the vulnerability of European aquatic insects to climate change. Hydrobiologia, 721 ,

$328 \quad 297-315$.

329

330 Dankers, R., \& Feyen, L. (2008). Climate change impact on flood hazard in Europe: An

331 assessment based on high resolution climate simulations. Journal of Geophysical Research, $332113, \mathrm{D} 19105$.

333

334 Dempson, B., Schwarz, C. J., Bradbury, I. R., Robertson, M. J., Veinott, G., Poole, R., \& 
335 Colbourne, E. (2017). Influence of climate and abundance on migration timing of adult

336 Atlantic salmon (Salmo salar) among rivers in Newfoundland and Labrador. Ecology of

337 Freshwater Fish, 26, 247-259.

EEA (2012). Climate Change, Impacts and Vulnerability in Europe 2012: An Indicator-Based

342 EEA (2017). Climate Change, Impacts and Vulnerability in Europe 2016: An Indicator-Based

343 Report. EEA Report No 1/2017. Copenhagen: European Environment Agency.

345 Elith, J., Leathwick, J. R., \& Hastie, T. (2008). A working guide to boosted regression trees.

348 ESPON Climate (2011). Climate Change and Territorial Effects on Regions and Local

349 Economies (Scientific Report). Institute of Spatial Planning (IRPUD), TU Dortmund

350 University. http://www.espon.eu/main/Menu_Projects/Menu_AppliedResearch/climate.html.

351 Accessed 20 June 2018

352

353 Ficke, A. D., Myrick, C. A., \& Hansen, L. J. (2007). Potential impacts of global climate

354 change on freshwater fisheries. Reviews in Fish Biology and Fisheries, 17, 581-613.

356 Fischer, E. M., \& Schär, C. (2010). Consistent geographical patterns of changes in high-

357 impact European heatwaves. Nature Geoscience, 3, 398-403. 
359 Floeter, S. R., Bender, M. G., Siqueira, A. C., \& Cowman, P. F. (2018). Phylogenetic

360 perspectives on reef fish functional traits. Biological Reviews, 93, 131-151.

361

362 Foden, W. B., Butchart, S. H., Stuart, S. N., Vié, J. C., Akçakaya, H. R., Angulo, A., ... \&

363 Donner, S. D. (2013). Identifying the world's most climate change vulnerable species: a

364 systematic trait-based assessment of all birds, amphibians and corals. PloS One, 8, e65427.

365

366 Froese, R., \& Pauly, D. (Eds.) (2017). FishBase. World Wide Web electronic publication.

367 version 10/2017. https://www.fishbase.org. Accessed 15 January 2018

368

369 Graham, C. T., \& Harrod, C. (2009). Implications of climate change for the fishes of the

370 British Isles. Journal of Fish Biology, 74, 1143-1205.

371

372 Harrod, C. (2016). Climate change and freshwater fisheries. In J. F. Craig (Ed.), Freshwater

373 Fisheries Ecology (pp. 641-694). John Wiley \& Sons.

374

375 Hering, D., Schmidt-Kloiber, A., Murphy, J., Lücke, S., Zamora-Munoz, C., López-

376 Rodríguez, M. J., ... \& Graf, W. (2009). Potential impact of climate change on aquatic insects:

377 a sensitivity analysis for European caddisflies (Trichoptera) based on distribution patterns and

378 ecological preferences. Aquatic Sciences, 71, 3-14.

379

380 Hijmans, R. J. (2017). Raster: Geographic Data Analysis and Modeling. R package version

381 2.6-7. https://CRAN.R-project.org/package=raster. Accessed 20 June 2018 
383 Hijmans, R. J., \& Elith, J. (2017). Species distribution modeling with R. R vignette.

384 https://cran.r-project.org/web/packages/dismo/vignettes/sdm.pdf. Accessed 20 June 2018

385

386 Hijmans, R. J., Phillips, S., Leathwick, J., \& Elith, J. (2017). Dismo: Species distribution

387 modeling. http://cran.r-project.org/package=dismo. Accessed 20 June 2018

388

389 Hovel, R. A., Carlson, S. M., \& Quinn, T. P. (2017). Climate change alters the reproductive

390 phenology and investment of a lacustrine fish, the three-spine stickleback. Global Change

391 Biology, 23, 2308-2320.

392

393 Isaak, D. J., \& Rieman, B. E. (2013). Stream isotherm shifts from climate change and

394 implications for distributions of ectothermic organisms. Global Change Biology, 19, 742-751.

395

396 IUCN (2017). The IUCN Red List of Threatened Species. Version 2017-1.

397 https://www.iucnredlist.org. Accessed 15 January 2018

398

399 Jacob, D., Petersen, J., Eggert, B., Alias, A., Christensen, O. B., Bouwer, L. M., ... \&

400 Georgopoulou, E. (2014). EURO-CORDEX: new high-resolution climate change projections

401 for European impact research. Regional Environmental Change, 14, 563-578.

402

403 Jiguet, F., Gadot, A. S., Julliard, R., Newson, S. E., \& Couvet, D. (2007). Climate envelope,

404 life history traits and the resilience of birds facing global change. Global Change Biology, 13, $405 \quad 1672-1684$. 
407 Kalinkat, G., Jähnig, S. C., \& Jeschke, J. M. (2017). Exceptional body size-extinction risk

408 relations shed new light on the freshwater biodiversity crisis. Proceedings of the National

409 Academy of Sciences, 201717087.

410

411 Keith, D. A., Mahony, M., Hines, H., Elith, J., Regan, T. J., Baumgartner, J. B., ... \& Penman,

412 T. (2014). Detecting extinction risk from climate change by IUCN Red List criteria.

413 Conservation Biology, 28, 810-819.

414

415 Kopf, R. K., Shaw, C., \& Humphries, P. (2017). Trait based prediction of extinction risk of

416 small bodied freshwater fishes. Conservation Biology, 31, 581-591.

417

418 Levinsky, I., Skov, F., Svenning, J. C., \& Rahbek, C. (2007). Potential impacts of climate

419 change on the distributions and diversity patterns of European mammals. Biodiversity and

420 Conservation, 16, 3803-3816.

421

422 Liu, C., Comte, L., \& Olden, J. D. (2017). Heads you win, tails you lose: Life history traits

423 predict invasion and extinction risk of the world's freshwater fishes. Aquatic Conservation:

424 Marine and Freshwater Ecosystems, 27, 773-779.

425

426 MacLean, S. A., \& Beissinger, S. R. (2017). Species' traits as predictors of range shifts under

427 contemporary climate change: a review and meta analysis. Global Change Biology, 23,

428 4094-4105.

429

430 McDonald-Madden, E., Chadès, I., McCarthy, M. A., Linkie, M., \& Possingham, H. P. (2011). 
431 Allocating conservation resources between areas where persistence of a species is uncertain.

432 Ecological Applications, 21, 844-858.

433

434 Milly, P. C., Dunne, K. A., \& Vecchia, A. V. (2005). Global pattern of trends in streamflow 435 and water availability in a changing climate. Nature, 438, 347-350.

437 Olden, J. D., Hogan, Z. S., \& Zanden, M. J. V. (2007). Small fish, big fish, red fish, blue fish:

438 size-biased extinction risk of the world's freshwater and marine fishes. Global Ecology and 439 Biogeography, 16, 694-701.

441 O’Reilly, C. M., Alin, S. R., Plisnier, P. D., Cohen, A. S., \& McKee, B. A. (2003). Climate

442 change decreases aquatic ecosystem productivity of Lake Tanganyika, Africa. Nature, 424, 443 766-768.

445 Otero, J., L’Abée Lund, J. H., Castro-Santos, T., Leonardsson, K., Storvik, G. O., Jonsson, 446 B., ... \& Dionne, M. (2014). Basin scale phenology and effects of climate variability on 447 global timing of initial seaward migration of Atlantic salmon (Salmo salar). Global Change 448 Biology, 20, 61-75.

450 Pacifici, M., Foden, W. B., Visconti, P., Watson, J. E., Butchart, S. H., Kovacs, K. M., ... \& 451 Corlett, R. T. (2015). Assessing species vulnerability to climate change. Nature Climate 452 Change, 5, 215-225.

454 Payne, N. L., \& Smith, J. A. (2017). An alternative explanation for global trends in thermal 
tolerance. Ecology Letters, 20, 70-77.

457 Payne, N. L., Smith, J. A., Meulen, D. E., Taylor, M. D., Watanabe, Y. Y., Takahashi, A., ... \&

458 Suthers, I. M. (2016). Temperature dependence of fish performance in the wild: links with

459 species biogeography and physiological thermal tolerance. Functional Ecology, 30, 903-912.

460

461 Pearson, R. G., Stanton, J. C., Shoemaker, K. T., Aiello-Lammens, M. E., Ersts, P. J., Horning,

462 N., ... \& Akçakaya, H. R. (2014). Life history and spatial traits predict extinction risk due to

463 climate change. Nature Climate Change, 4, 217-221.

464

465 Peng, R. D. (2008). Simple bootstrap routines. https://cran.r-project.org/package=simpleboot.

466 Accessed 20 June 2018

467

468 Pörtner, H. O., \& Farrell, A. P. (2008). Physiology and climate change. Science, 322, 690-692.

470 Punt, A. E., Smith, D. C., \& Smith, A. D. (2011). Among-stock comparisons for improving

471 stock assessments of data-poor stocks: the "Robin Hood" approach. ICES Journal of Marine

472 Science, 68, 972-981.

473

474 R Development Core Team (2017). R: A language and environment for statistical computing.

475 R Foundation for Statistical Computing, Vienna, Austria.

477 Radinger, J., \& Wolter, C. (2014). Patterns and predictors of fish dispersal in rivers. Fish and 478 Fisheries, 15, 456-473. 
480 Radinger, J., Wolter, C., \& Kail, J. (2015). Spatial Scaling of Environmental Variables

481 Improves Species-Habitat Models of Fishes in a Small, Sand-Bed Lowland River. PLoS One, $48210, \mathrm{e} 0142813$.

484 Radinger, J., Hölker, F., Horký, P., Slavík, O., Dendoncker, N., \& Wolter, C. (2016).

485 Synergistic and antagonistic interactions of future land use and climate change on river fish 486 assemblages. Global Change Biology, 22, 1505-1522.

488 Radinger, J., Essl, F., Hölker, F., Horký, P., Slavík, O., \& Wolter, C. (2017). The future

489 distribution of river fish: the complex interplay of climate and land use changes, species

490 dispersal and movement barriers. Global Change Biology, 23, 4970-4986.

492 Raptis, C. E., Boucher, J. M., \& Pfister, S. (2017). Assessing the environmental impacts of

493 freshwater thermal pollution from global power generation in LCA. Science of the Total

494 Environment, 580, 1014-1026.

Rojas, R., Feyen, L., Bianchi, A., \& Dosio, A. (2012). Assessment of future flood hazard in

497 Europe using a large ensemble of bias corrected regional climate simulations. Journal of

498 Geophysical Research, 117, D17109.

500 Russo, S., Dosio, A., Graversen, R. G., Sillmann, J., Carrao, H., Dunbar, M. B., ... \& Vogt, J.

501 V. (2014). Magnitude of extreme heat waves in present climate and their projection in a

502 warming world. Journal of Geophysical Research: Atmospheres, 119, 12500-12512. 
504 Sinclair, B. J., Marshall, K. E., Sewell, M. A., Levesque, D. L., Willett, C. S., Slotsbo, S., ... \&

505 Huey, R. B. (2016). Can we predict ectotherm responses to climate change using thermal

506 performance curves and body temperatures?. Ecology Letters, 19, 1372-1385.

507

508 Stagge, J. H., Rizzi, J., Tallaksen, L. M., \& Stahl, K. (2015). Future meteorological drought:

509 projections of regional climate models for Europe. In EGU General Assembly Conference

510 Abstracts (Vol. 17). Technical Report No. 25, DROUGHT-R\&SPI, European Commission.

512 Trull, N., Böhm, M., \& Carr, J. (2018). Patterns and biases of climate change threats in the

513 IUCN Red List. Conservation Biology, 32, 135-147.

514

515 USGS (2010). Global Multi-resolution Terrain Elevation Data 2010 (GMTED2010). U.S.

516 Geological Survey (USGS). https://topotools.cr.usgs.gov/gmted_viewer. Accessed 15 January

$517 \quad 2018$

518

519 Vega, G. C., Pertierra, L. R., \& Olalla-Tárraga, M. Á. (2017). MERRAclim, a high-resolution

520 global dataset of remotely sensed bioclimatic variables for ecological modelling. Scientific

$521 \quad$ Data, 4, 170078.

522

523 Vörösmarty, C. J., McIntyre, P. B., Gessner, M. O., Dudgeon, D., Prusevich, A., Green, P., ...

524 \& Davies, P. M. (2010). Global threats to human water security and river biodiversity. Nature, $525467,555-561$. 
527 Walther, G. R., Roques, A., Hulme, P. E., Sykes, M. T., Pyšek, P., Kühn, I., ... \& Czucz, B.

528 (2009). Alien species in a warmer world: risks and opportunities. Trends in Ecology and

529 Evolution, 24, 686-693.

530

531 WCS, \& CIESIN (2005). Last of the Wild Project, Version 2, 2005 (LWP-2): Global Human

532 Footprint Dataset (IGHP). Wildlife Conservation Society (WCS) and and Center for

533 International Earth Science Information Network (CIESIN), Columbia University. Palisades,

534 NY: NASA Socioeconomic Data and Applications Center (SEDAC).

535 http://dx.doi.org/10.7927/H4GF0RFQ. Accessed 15 January 2018

536

537 WRI (2006). World Resources Institute (WRI) Major Watersheds of the World Delineation.

538 FAO GeoNetwork, FAO - Aquaculture Management and Conservation Service (FIMA).

539 http://www.fao.org/geonetwork/srv/en/metadata.show?id=30914. Accessed 15 January 2018

541 Xenopoulos, M. A., Lodge, D. M., Alcamo, J., Märker, M., Schulze, K., \& Van Vuuren, D. P.

542 (2005). Scenarios of freshwater fish extinctions from climate change and water withdrawal.

543 Global Change Biology, 11, 1557-1564.

544

545

546

547

548

549

550 
Table 1. Variables used in the analysis, with their data sources, general descriptive statistics and coverage (proportion of species with available data). See Supplemetary material I for more information.

\begin{tabular}{|c|c|c|c|c|}
\hline & Variable name & Data source & Median; mean $\pm \mathrm{SD}$ (range); proportions (\%) for categorical data & $\begin{array}{l}\text { Coverage } \\
(\%)\end{array}$ \\
\hline 1 & Game fish & FishBase & Yes: 14 , No: 86 & 100 \\
\hline 2 & IUCN Red List status & FishBase/IUCN & EX: 3, CR: 12, EN: 11, VU: 16, NT: 4, LC: 48, DD: 6 & 100 \\
\hline 3 & Climate zone (Köppen climate classification) & FishBase & Subtropical: 26 , temperate 73 , polar: 1 & 100 \\
\hline 4 & Preferred habitat & FishBase & Pelagic: 3 , pelagic-neritic: 3 , benthopelagic: 64 , demersal: 30 & 100 \\
\hline 5 & Minimum value of the water depth range $(\mathrm{m})$ & FishBase & $2 ; 11.2 \pm 17.9(0-100)$ & 18 \\
\hline 6 & Maximum value of the water depth range (m) & FishBase & $80 ; 106.7 \pm 138.8(1-700)$ & 14 \\
\hline 7 & Freshwater preference & FishBase & Exlusively freshwater: 75 , enters saltwater: 25 & 100 \\
\hline 8 & Maximum recorded body length $(\mathrm{cm})$ & FishBase & $21.7 ; 35.2 \pm 60.5(2.2-800)$ & 98 \\
\hline 9 & Lateral body shape type & FishBase & Eel-like: 1 , elongated: 38 , fusiform/normal: 59 , short and/or deep: 1 & 77 \\
\hline 10 & Aspect ratio of the caudal fin & FishBase & $1.6 ; 1.6 \pm 0.6(0.4-3.4)$ & 34 \\
\hline 11 & Trophic level & FishBase & $3.3 ; 3.4 \pm 0.6(2.1-4.5)$ & 13 \\
\hline 12 & Batch spawner & FishBase & Yes: 12 , no: 88 & 55 \\
\hline 13 & Reproductive guild (first classification) & FishBase & Bearers: 1 , guarders: 18 , nonguarders: 81 & 53 \\
\hline 14 & Reproductive guild (second classification) & FishBase & $\begin{array}{l}\text { Brood hiders: } 10 \text {, clutch tenders: } 5 \text {, external brooders: } 10 \text {, internal } \\
\text { live bearers: } 2 \text {, nesters: } 18 \text {, open water/substratum egg scatterers: } 57\end{array}$ & 28 \\
\hline 15 & Maximum recorded longevity (years) & FishBase & $9 ; 13.8 \pm 17.4(1-118)$ & 30 \\
\hline 16 & Commercial importance & FishBase & $\begin{array}{l}\text { Of no interest: } 41 \text {, subsistence fisheries: } 4 \text {, minor commercial: } 15 \text {, } \\
\text { commercial: } 35 \text {, highly commercial: } 5\end{array}$ & 40 \\
\hline 17 & Average global landings/production & FishBase & $828.4 ; 10461.4 \pm 23020.9(0-104902.8)$ & 12 \\
\hline 18 & Resilience to fishing pressure & FishBase & $1: 3,2: 12,3: 58,4: 27$ & 100 \\
\hline 19 & Vulnerability to fishing & FishBase & $32.9 ; 36.5 \pm 16.6(10-88.7)$ & 100 \\
\hline 20 & Temperature tolerance ( $\max$ - $\min$ reported $\mathrm{T},{ }^{\circ} \mathrm{C}$ ) & FishBase & $15 ; 14.4 \pm 5.2(1-32)$ & 21 \\
\hline 21 & Number of inhabited freshwater basins & WRI (2006)/IUCN(range) & $2 ; 8.5 \pm 14.6(0-82)$ & 96 \\
\hline 22 & Global Human Footprint & $\begin{array}{l}\text { WCS \& CIESIN } \\
(2005) / \text { IUCN(range) }\end{array}$ & $6 ; 7.8 \pm 7.8(0-46)$ & 96 \\
\hline 23 & Longitude of the centroid of species range & IUCN(range) & $18.6 ; 17.2 \pm 17.4(-81.1-117.2)$ & 96 \\
\hline
\end{tabular}


Specific humidity of the least humid quarter (g water / kg air)

44 Specific humidity of the warmest quarter ( $\mathrm{g}$ water / $\mathrm{kg}$ air)

45 Specific humidity of the coldest quarter (g water / kg air) of air)

Specific humidity of the least humid month (g water / kg air)

Specific humidity seasonality (g water / kg air)
USGS (2010)/IUCN(range) $590.4 ; 833.8 \pm 652.5$ (3.9 - 2373.6)

MERRAclim/IUCN(range) $13.5 ; 13.4 \pm 4.1$ (-3.7 - 22.7)

MERRAclim/IUCN(range) $19.9 ; 19.5 \pm 2.9$ (7.2 - 27.0)

MERRAclim/IUCN(range) $44.9 ; 45.3 \pm 3.9$ (34.5 - 55.0)

MERRAclim/IUCN(range) $780.6 ; 800.0 \pm 180.6(312.6-1515.3)$

MERRAclim/IUCN(range) $35.7 ; 35.0 \pm 4.6(20.3-43.2)$

MERRAclim/IUCN(range) $\quad-8.6 ;-8.5 \pm 7.6$ (-36.4 - 8.8)

MERRAclim/IUCN(range) $43.3 ; 43.5 \pm 7.5(17.1$ - 65.9)

MERRAclim/IUCN(range) $22.9 ; 22.7 \pm 3.5(10.8-30.5)$

MERRAclim/IUCN(range) $\quad 4.2 ; 3.9 \pm 5.8(-19.8-16.5)$

MERRAclim/IUCN(range) $23.2 ; 23.1 \pm 3.7$ (11.0 - 31.0)

MERRAclim/IUCN(range) $3.9 ; 3.6 \pm 5.7$ (-19.9 - 15.6)

MERRAclim/IUCN(range) $7.2 ; 7.2 \pm 0.9(3.5-10.1)$

Specific humidity of the most humid month ( $\mathrm{g}$ of water $/ \mathrm{kg}$ MERRAclim/IUCN(range) $11.2 ; 11.1 \pm 1.0(6.7$ - 14.3)

MERRAclim/IUCN(range) $4.0 ; 4.0 \pm 1.1(0.8-7.1)$

MERRAclim/IUCN(range) $255.4 ; 249.7 \pm 52.3(123.0-395.5) \quad 96$

MERRAclim/IUCN(range) $10.4 ; 10.4 \pm 1.0(6.2$ - 13.6) 96

MERRAclim/IUCN(range) $4.5 ; 4.4 \pm 1.1(1.0-7.5)$

MERRAclim/IUCN(range) $10.3 ; 10.3 \pm 1.0(6.2$ - 13.3) 96

MERRAclim/IUCN(range) $\quad 4.5 ; 4.4 \pm 1.2(1.0$ - 7.6) 96 


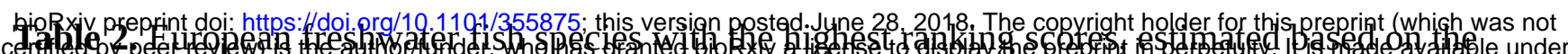

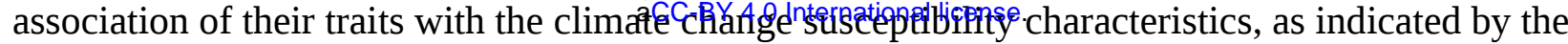
BRT model. Complete ranking list of all species is presented in Supplementary material 5.

\begin{tabular}{|c|c|c|c|c|}
\hline Rank & Species & $\begin{array}{l}\text { Climate change } \\
\text { susceptibility }\end{array}$ & $\begin{array}{l}\text { IUCN Red List } \\
\text { category }\end{array}$ & Ranking score \\
\hline 1 & Knipowitschia milleri & non-susceptible & $\mathrm{CR}$ & 82.5 \\
\hline 2 & Valencia letourneuxi & susceptible & $\mathrm{CR}$ & 82.1 \\
\hline 3 & Iberochondrostoma almacai & susceptible & $\mathrm{CR}$ & 81.6 \\
\hline 4 & Barbus euboicus & susceptible & $\mathrm{CR}$ & 81.4 \\
\hline 5 & Squalius malacitanus & non-susceptible & EN & 80.9 \\
\hline 6 & Aphanius baeticus & susceptible & EN & 80.7 \\
\hline 7 & Knipowitschia goerneri & susceptible & $\mathrm{DD}$ & 80.5 \\
\hline 8 & Squalius keadicus & susceptible & $\mathrm{EN}$ & 80.5 \\
\hline 9 & Pelasgus laconicus & susceptible & $\mathrm{CR}$ & 80.4 \\
\hline 10 & Tropidophoxinellus spartiaticus & susceptible & VU & 80.3 \\
\hline 11 & Iberocypris palaciosi & susceptible & $\mathrm{CR}$ & 80.1 \\
\hline 12 & Pelasgus epiroticus & susceptible & $\mathrm{CR}$ & 80.0 \\
\hline 13 & Aphanius almiriensis & non-susceptible & $\mathrm{CR}$ & 79.8 \\
\hline 14 & Anaecypris hispanica & susceptible & EN & 79.5 \\
\hline 15 & Salaria economidisi & susceptible & $\mathrm{CR}$ & 79.5 \\
\hline 16 & Squalius torgalensis & susceptible & EN & 79.4 \\
\hline 17 & Cobitis trichonica & susceptible & EN & 78.9 \\
\hline 18 & Valencia hispanica & susceptible & $\mathrm{CR}$ & 78.6 \\
\hline 19 & Economidichthys trichonis & non-susceptible & EN & 78.6 \\
\hline 20 & Knipowitschia thessala & susceptible & EN & 78.5 \\
\hline
\end{tabular}


bioRxiv preprint doi: https://doi.org/10.1101/355875; this version posted June 28, 2018. The copyright holder for this preprint (which was not certified by peer review) is the author/funder, who has granted bioRxiv a license to display the preprint in perpetuity. It is made available under 1 Figure captions:

3 Figure 1. Variables selected by the boosted regression tree (BRT) model as the most relevant

4 descriptors of climate change susceptibility in European freshwater fish species; 20 most

5 relevant variables are presented, which together account for $90 \%$ of the total relative variable

6 influence.

8 Figure 2. Violin-boxplots and barplots of the most relevant spatial variables in European

9 freshwater fish species indicated as either susceptible $(\mathrm{n}=148)$ or non-susceptible $(\mathrm{n}=295)$

10 to climate change. Habitat preference: blue - exclusively freshwater species, green - species

11 that also enter saltwater.

12

13 Figure 3. Violin-boxplots and barplots of the most relevant life history traits and variables

14 related to threat and commercial status in European freshwater fish species indicated as either

15 susceptible $(n=148)$ or non-susceptible $(n=295)$ to climate change.

16

17 Figure 4. Richness of freshwater fish species across Europe indicated as either susceptible

18 (middle panel) or non-susceptible (left panel) to climate change, and the relative share of

19 susceptible species in the local total species richness (right panel). 
Latitude of the species range centroid IUCN Red List classsification

Commercial relevance Vulnerability to fishing Maximum body length Mean diurnal temperature range Annual temperature range Annual mean specific humidity Temperature seasonality

Range size

Mean elevation within the species range Maximum temperature of the warmest month

Human footprint within the species range Mean temperature of the most humid quarter

Annual mean temperature

Temperature isothermality Longitude of the species range centroid Freshwater preference Mean humidity of the least humid quarter Mean temperature of the warmest quarter

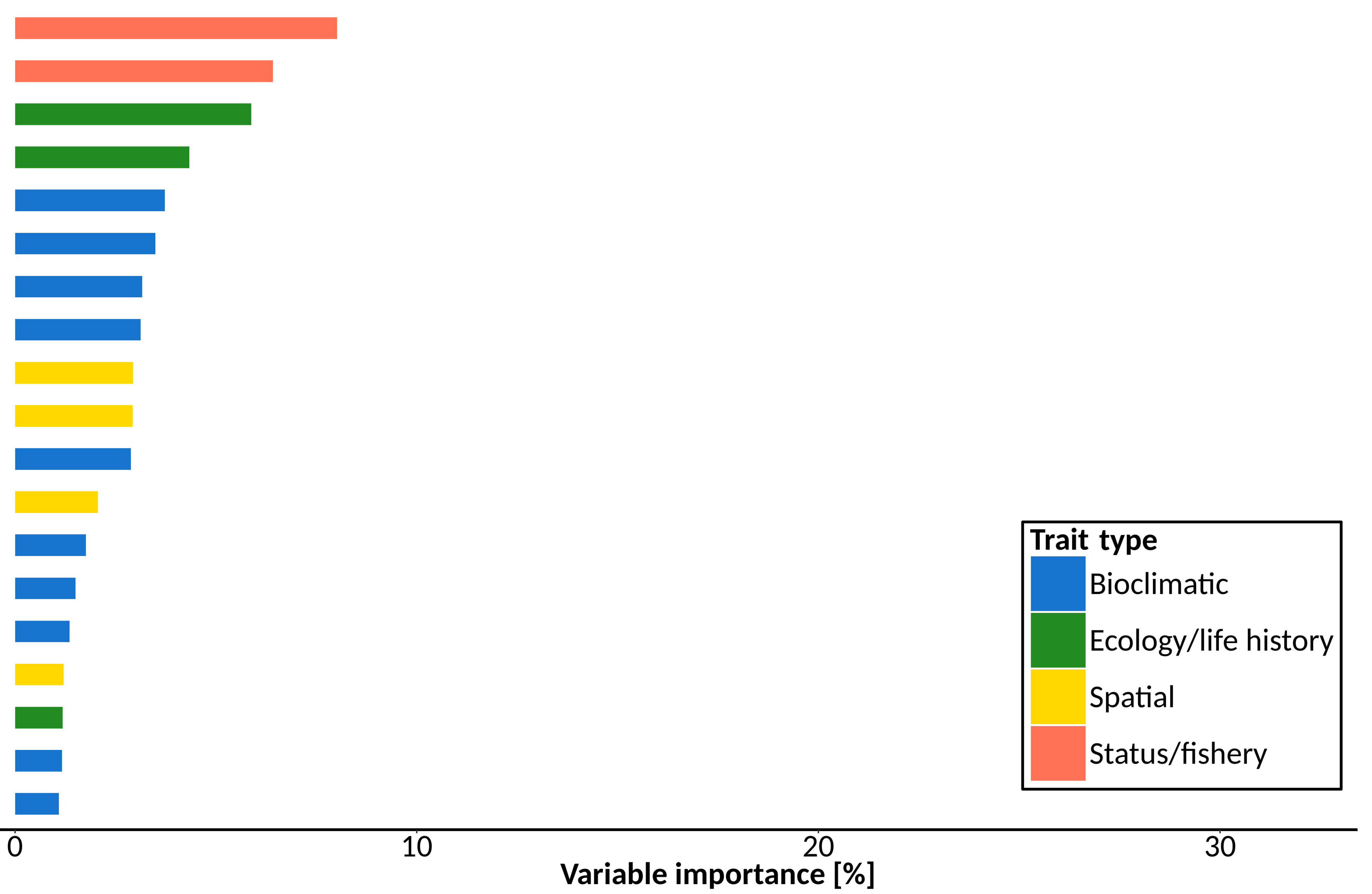




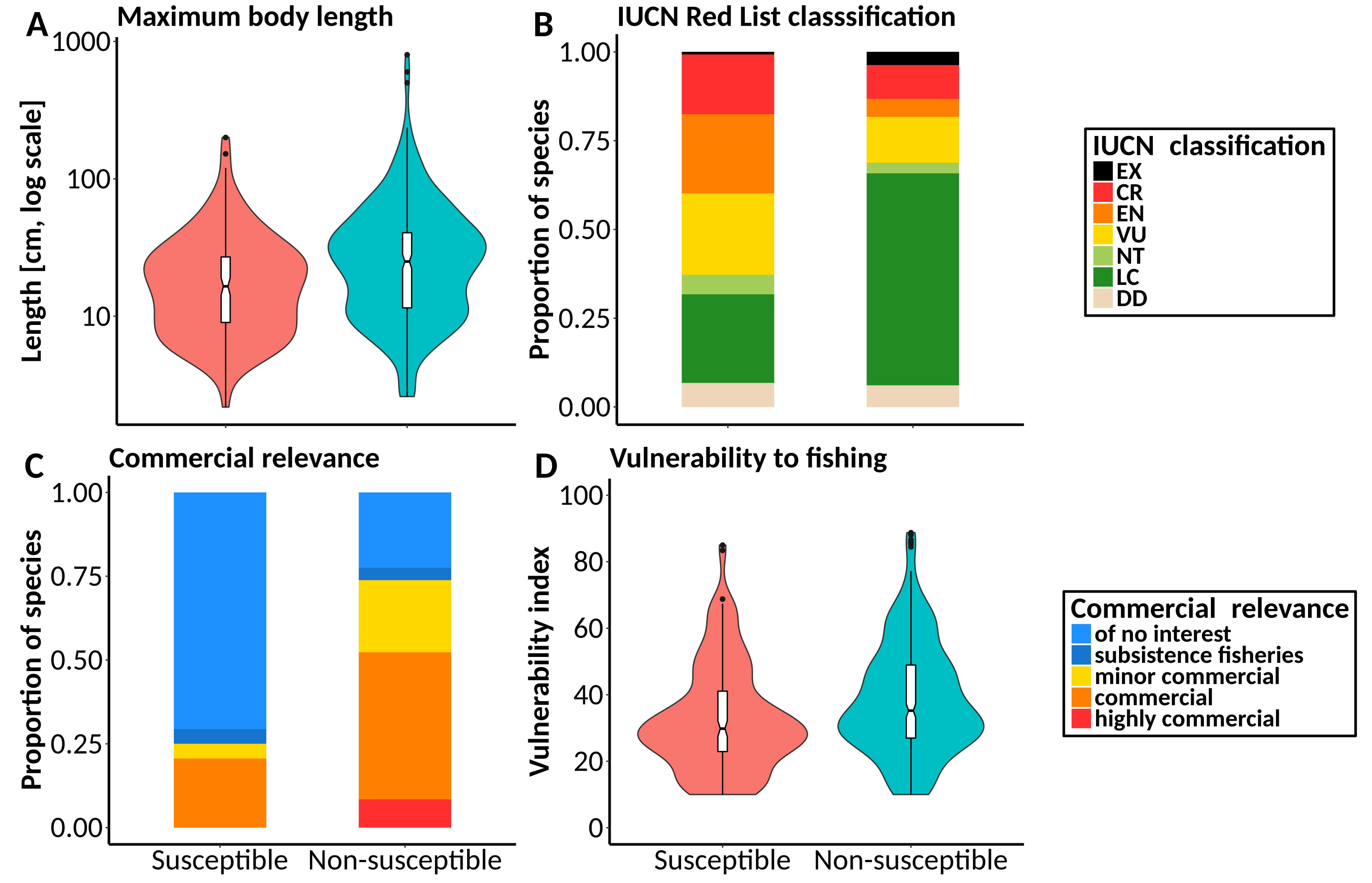




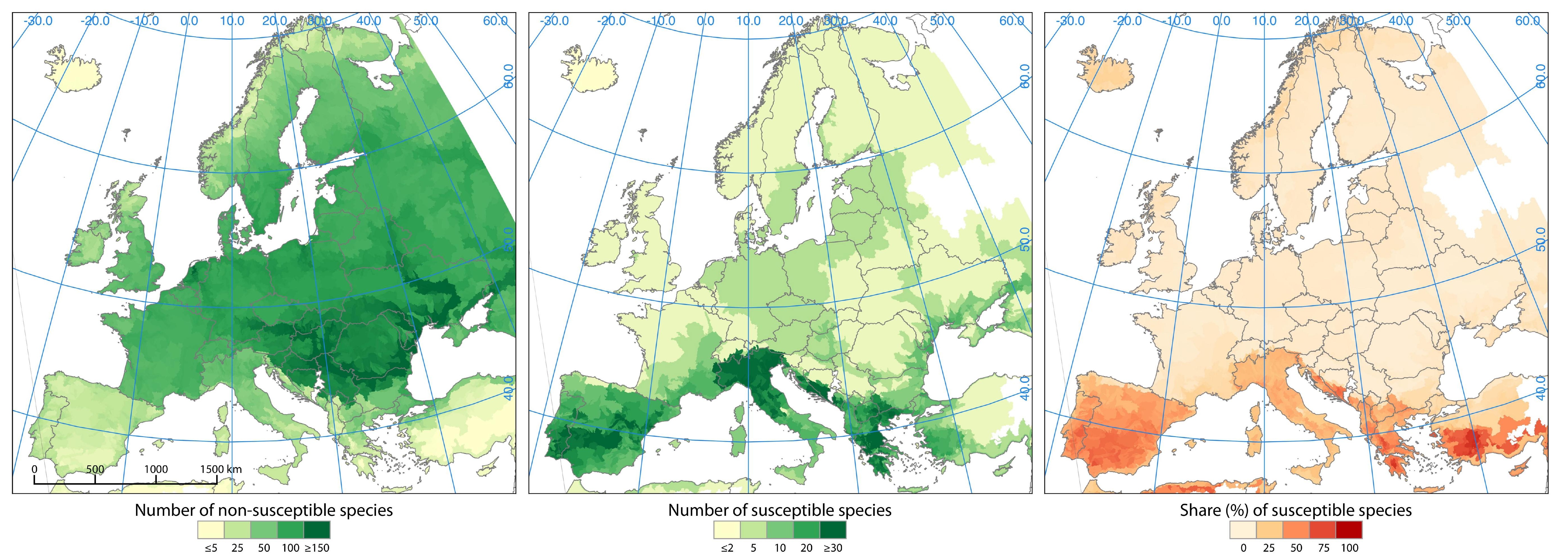

